\title{
A Study on the Reduction of Cogging Force of Stationary Discontinuous Armature Linear Synchronous Motor Using Auxiliary Teeth
}

\author{
Yong-Jae Kim ${ }^{1}$, Kyu Myung Lee ${ }^{1 *}$, and Masaya Watada ${ }^{2}$ \\ ${ }^{1}$ Dept. of Electrical Engineering, Chosun University, Gwangju 501-759, Korea \\ ${ }^{2}$ Dept. of Biomedical Engineering, Tokyo City University, Tokyo 158-8557, Japan
}

(Received 13 June 2011, Received in final form 1 July 2011, Accepted 4 July 2011)

\begin{abstract}
The stationary discontinuous armatures that are used in permanent magnet linear synchronous motors (PMLSMs) have been proposed as a driving source for transportation systems. However, the stationary discontinuous armature PM-LSM contains the outlet edges which always exist as a result of the discontinuous arrangement of the armature. For this reason, the high alteration of the outlet edge cogging force produced between the armature's core and the mover's permanent magnet when a mover passes the boundary between the armature's installation part and non-installation part has been indicated as a problem. Therefore, we have examined the outlet edge cogging force by installing the auxiliary teeth at the armature's outlet edge in order to minimize the outlet edge cogging force generated when the armature is arranged discontinuously. Moreover, we obtained the calculation by analyzing the shape of the auxiliary teeth in which the outlet edge cogging force is minimized the most.
\end{abstract}

Keywords : transportation system, linear synchronous motor, outlet edge cogging force, auxiliary teeth, 2-D numerical analysis

\section{Introduction}

Linear motors have become popular in the field of factory automation where there is great demand for highspeed, low noise, simplification of driving apparatus and maintenance-free transportation [1-4]. Usually, in a transportation system using linear motors, a full-length (continuous) armature-side-on-ground design is employed. This design is very reliable although it is costly in longdistance transportation systems. Therefore, in order to resolve the problem of higher costs, the authors' laboratory has proposed a stationary discontinuous armature PMLSM in which the armature is engaged only when accelerated and decelerated operation is necessary when the PM-LSM is used with long-distance transportation systems in factories. Fig. 1 shows speed profiles of PM-LSM horizontal transportation systems. The mover is accelerated by the short armature unit (accelerator) and is then driven by its own inertia. Since the velocity of the mover decreases, the mover enters the next armature unit which is installed in order to make it re-accelerate and decelerate,

*Corresponding author: Tel: +82-62-230-7034

Fax:+82-62-230-7026, e-mail: bboy2778@naver.com and there it is re-accelerated and decelerated. However, the stationary discontinuous armature PM-LSM contains outlet edges, which always exist as a result of the discontinuous arrangement of the armature. For this reason, the outlet edge cogging force generated between the entrance end (entry interval) and the exit end (ejection interval) has become a problem. The problem is that the cogging force that operates at each outlet edge affects the mover's drive, so there is a possibility that hunting occurs during acceleration and deceleration when freewheeling changes over to re-acceleration and deceleration [5]. Therefore, a reduction of cogging force at each outlet edge is highly desirable in order to prevent the possibility of hunting occurring at re-acceleration and deceleration. We try to reduce the cogging force generated at the outlet edge by installing the auxiliary teeth at the outlet edge of the armature. We obtain the cogging force of the outlet edge by using 2-D numerical analysis with a finite element method (FEM) and also by adjusting the width, height and the length of pitch of auxiliary teeth. Moreover, we obtained the calculation by comparing the cogging force of the outlet edge of the basic model and of the proposed model by analyzing the shape of the auxiliary teeth in which the outlet edge cogging force is minimized the 


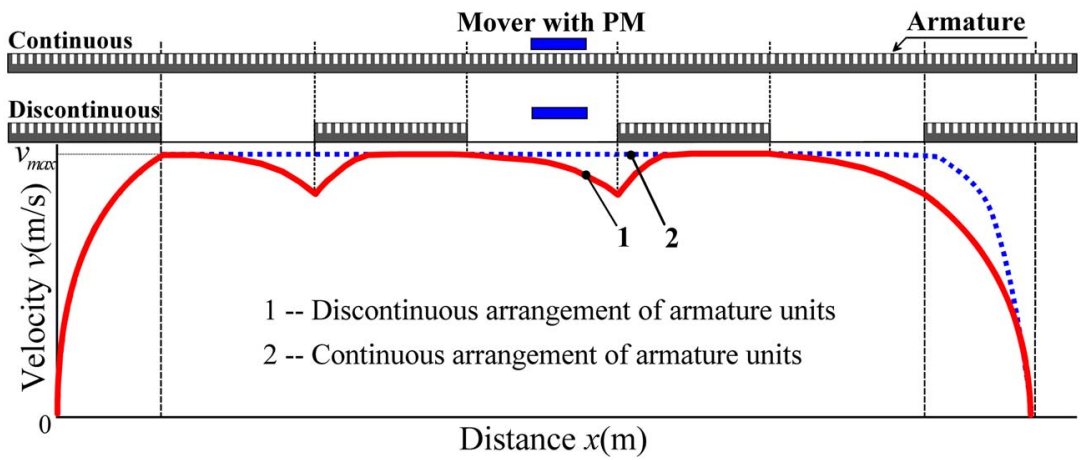

Fig. 1. (Color online) Speed profiles of PM-LSM horizontal transportation systems.

most.

\section{Force Generated at the Outlet Edge}

Fig. 2 shows forces exerted in the mover at the outlet edge. Fig. 2, we can see that the force generated at the outlet edge has an effect on the mover. If the mover goes through the boundary between the installation part and the non-installation part of the armature of a stationary discontinuous armature PM-LSM, the attractive force produced between the armature's core and mover's permanent magnet fluctuates highly. The attractive force produced at the entry interval the mover is accelerated by a force, which pulls the mover into the armature area. On the other hand, the attractive force generated at the ejection interval the mover becomes decelerated by the force, which pulls the mover back to the armature area.

\section{2-D Numerical Analysis of the Outlet Edge Cogging Force}

\subsection{Basic model}

To examine the cogging force generated at each outlet edge, we used 2-D numerical analysis with a FEM. The general-purpose electromagnetic field analysis software
(JMAG-Studio) was used for 2-D numerical analysis. The basic model is shown in Fig. 3 and the dimensions of the basic model is shown Table 1. The method of analysis is as follows: after setting an air-gap of $5 \mathrm{~mm}$ between the armature and the mover, the mover enters the armature area at the moment when there is incomplete alignment between them and the mover move at intervals of $0.5 \mathrm{~mm}$ to the section that is completely beyond the armature area. The number of elements is 61200 , and the number of nodes is 31314 . The 2-D numerical analysis result of cogging force at the outlet edge is shown in Fig. 4. As indicated by Fig. 4, the outlet edge cogging force at the entry interval increases as the mover moves into the armature area due to the change in the number of magnetic poles which are aligned with the armature. However, the cogging force decreases at the complete alignment of the mover with the armature interval. Moreover, we found that outlet edge cogging force at the ejection interval increases as the mover passes through the armature area due to the change in the number of magnetic poles which are aligned with the armature. When the air-gap is $5 \mathrm{~mm}$, a maximum outlet edge cogging force of $13.4 \mathrm{~N}$ is generated at the entry and ejection intervals. On the other hand, a cogging force of $\pm 0.6 \mathrm{~N}$ is generated at the same time as the mover becomes completely aligned with the

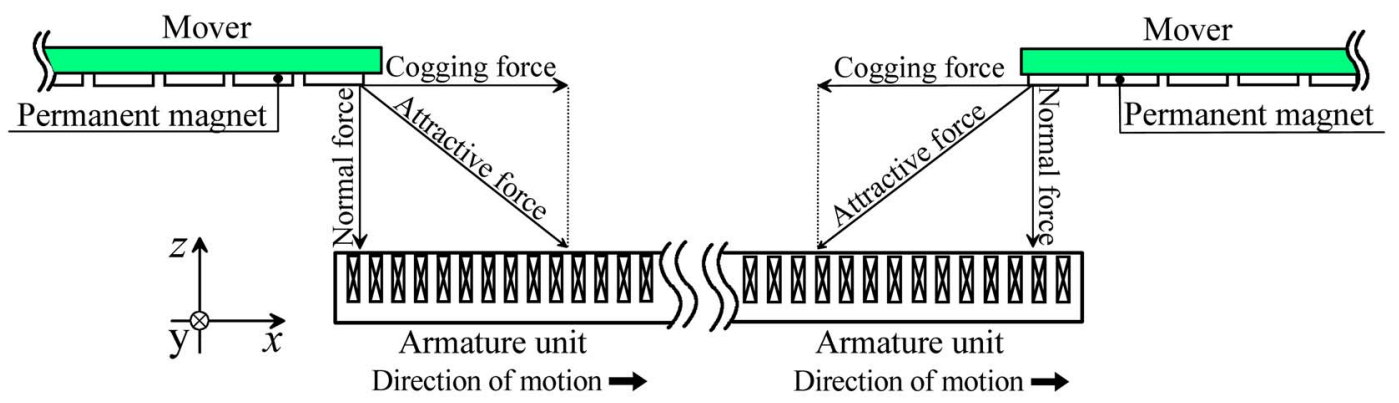

(a)

(b)

Fig. 2. (Color online) Forces exerted in the mover at the outlet edge: (a) entry interval (entrance end) and (b) ejection interval (exit end). 


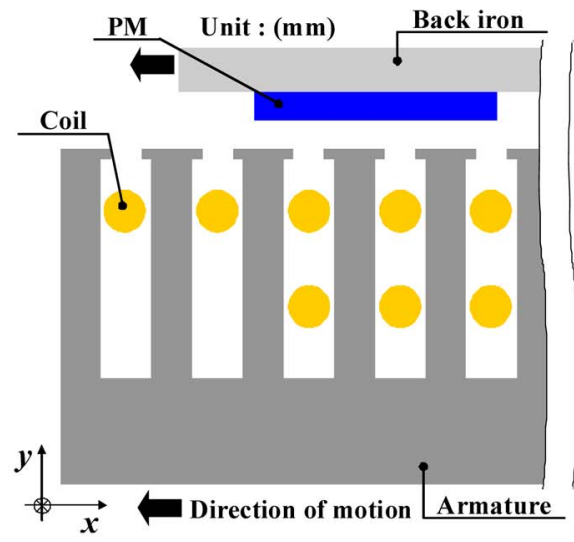

(a)

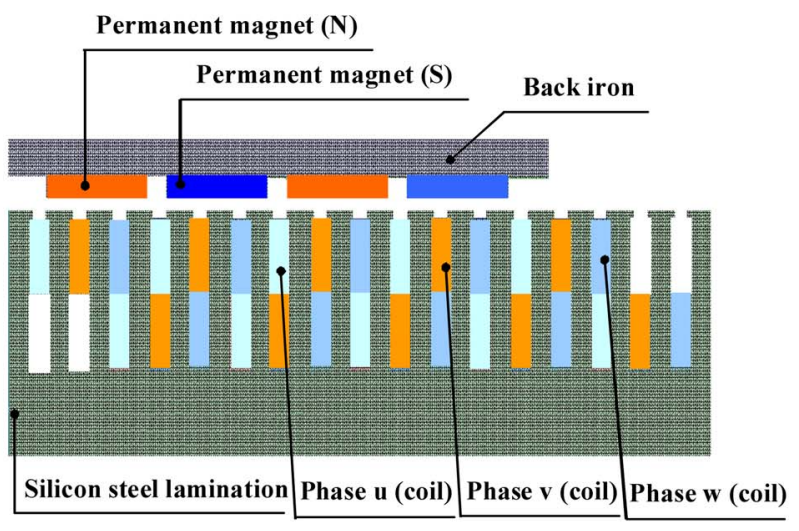

(b)

Fig. 3. (Color online) Basic model: (a) side view of the armature, (b) 2-D numerical analysis basic model.

Table 1. The dimensions of the basic model.

\begin{tabular}{|c|c|c|c|c|c|c|c|c|c|}
\hline \multirow{3}{*}{ Parameter } & \multicolumn{3}{|c|}{ Armature unit } & \multicolumn{5}{|c|}{ Mover with PM } & \multirow{3}{*}{ Airgap } \\
\hline & \multicolumn{2}{|c|}{ Width (x-axis) } & \multirow{2}{*}{$\begin{array}{c}\text { Length (y-axis) } \\
\text { Teeth }\end{array}$} & \multirow{2}{*}{$\begin{array}{c}\text { Number of } \\
\text { magnets }\end{array}$} & \multicolumn{3}{|c|}{ Magnet } & \multirow[b]{2}{*}{ Pole Pitch } & \\
\hline & Teeth & Slot & & & $\begin{array}{l}\text { Length } \\
\text { (x-axis) }\end{array}$ & $\begin{array}{l}\text { Width } \\
\text { (z-axis) }\end{array}$ & $\begin{array}{l}\text { Thickness } \\
\text { (y-axis) }\end{array}$ & & \\
\hline Value (Unit) & $5(\mathrm{~mm})$ & $5(\mathrm{~mm})$ & $23.5(\mathrm{~mm})$ & 4 (Poles) & $25(\mathrm{~mm})$ & $45(\mathrm{~mm})$ & $3(\mathrm{~mm})$ & $30(\mathrm{~mm})$ & $5(\mathrm{~mm})$ \\
\hline
\end{tabular}

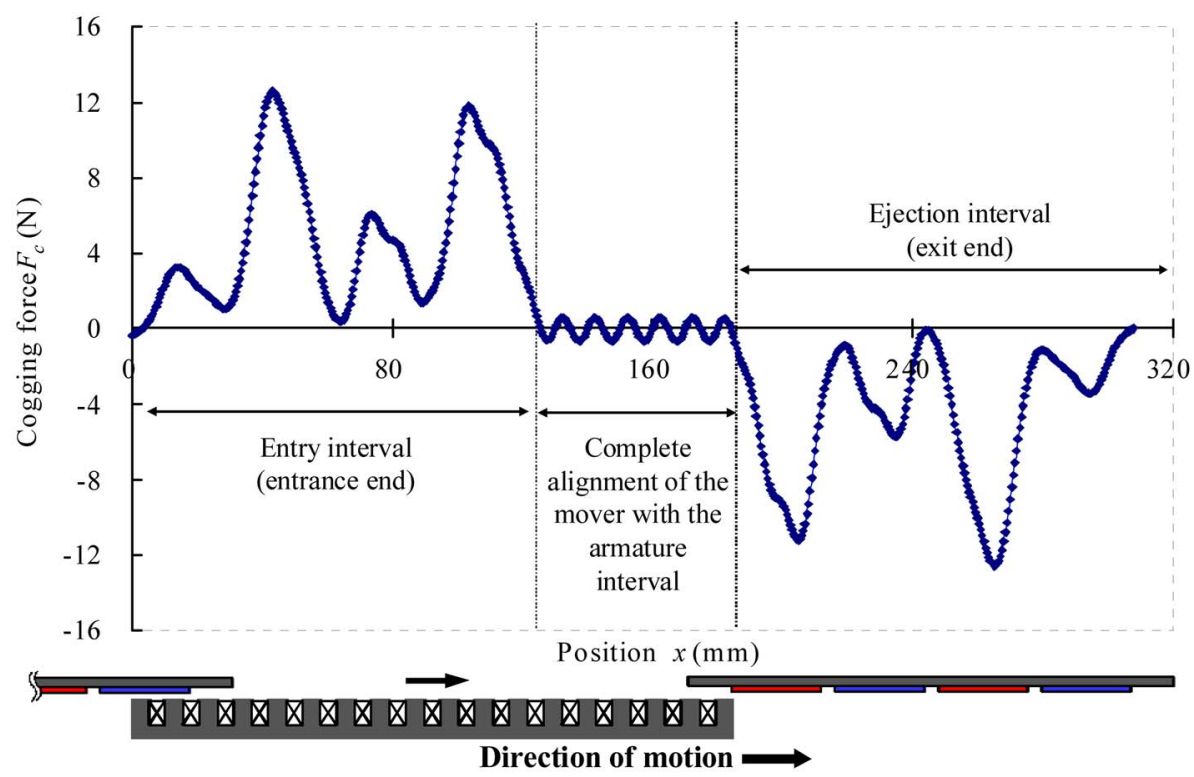

Fig. 4. (Color online) Outlet edge cogging force waveform of basic model.

armature. Therefore, we found that the cogging force in this situation is much less than the cogging force at each outlet edge.

\subsection{Proposed models with auxiliary teeth}

The proposed model is shown in Fig. 5 and the design parameters range of the auxiliary teeth is shown Table 2 . In order to reduce the cogging force at the outlet edge, we installed the auxiliary teeth at the end edge of the armature. By adjusting the pitch, height, width of the auxiliary teeth, we analyzed the cogging force generated at the outlet edge using 2-D numerical analysis with a FEM. 


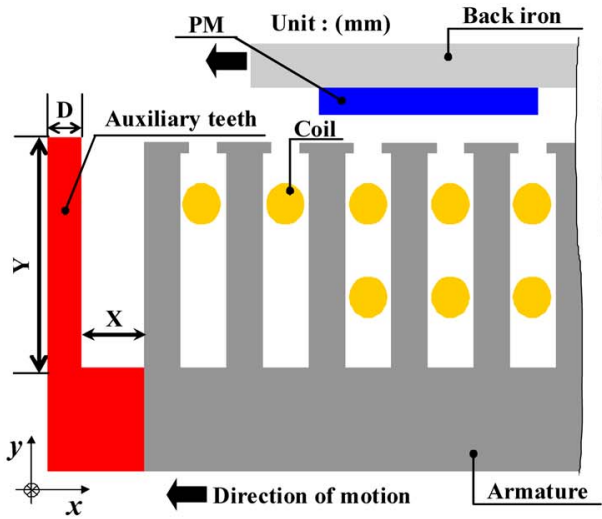

(a)

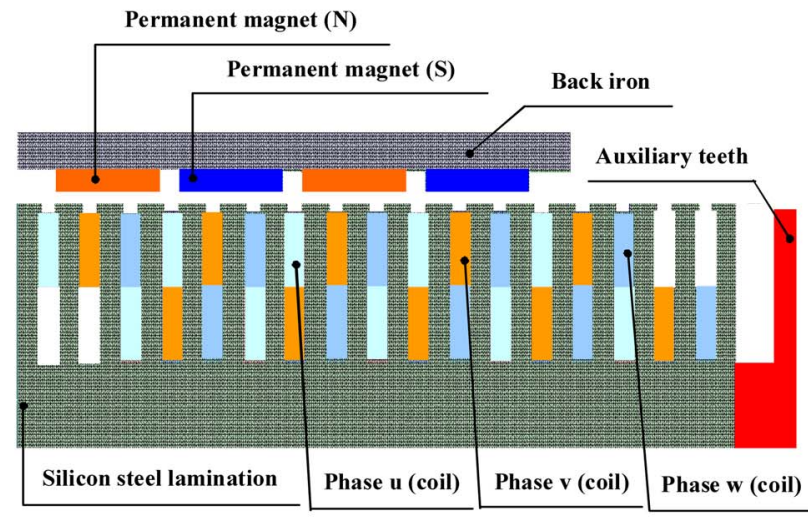

(b)

Fig. 5. (Color online) Proposed model: (a) side view of the armature and auxiliary teeth, (b) 2-D numerical analysis proposed model.

Table 2. The design parameters range of the auxiliary teeth.

\begin{tabular}{lc}
\hline \hline \multicolumn{1}{c}{ Parameter } & Parameter range \\
\hline Pitch of the auxiliary teeth $(\mathrm{X})$ & $2.5[\mathrm{~mm}] \sim 15[\mathrm{~mm}]$ \\
Height of the auxiliary teeth $(\mathrm{Y})$ & $6[\mathrm{~mm}] \sim 23.5[\mathrm{~mm}]$ \\
Width of the auxiliary teeth $(\mathrm{D})$ & $2.5[\mathrm{~mm}] \sim 20[\mathrm{~mm}]$ \\
\hline
\end{tabular}

The scale of analysis is from the armature area with the complete alignment of the mover to the end of the armature where the mover has completely exit.

A. The X-pitch adjustment of the design parameter of the auxiliary teeth

In case, the X-pitch is adjusted, the shape of the auxiliary teeth is shown Fig. 6. The X-pitch is adjusted $2.5 \mathrm{~mm}$ for Fig. 6(a), $5 \mathrm{~mm}$ for Fig. 6(b), $10 \mathrm{~mm}$ for Fig. 6(c), and $15 \mathrm{~mm}$ for Fig. 6(d). Also, we performed analysis by fixing the length of $Y$ and $D$ to $23.5 \mathrm{~mm}$ and $5 \mathrm{~mm}$ which are equal as the teeth of armature in basic model. Fig. 7 shows the outlet edge cogging force waveforms in case of adjusting X-pitch of the auxiliary teeth. As indi- cated by Fig. 7, when the X-pitch of the auxiliary teeth is adjusted, we can observe that the size of outlet edge cogging force increases when the X-pitch is increased. Moreover, we can observe that the position where the outlet edge cogging force is generated is changing. In case of proposed model \#1, its outlet edge's cogging force moved approximately $7.5 \mathrm{~mm}$ compared to the outlet edge cogging force of the basic model. The position of cogging force of the outlet edge has been moved $7.5 \mathrm{~mm}$ by the auxiliary teeth and this length is the sum of Xpitch $2.5 \mathrm{~mm}$ and the width of auxiliary teeth which is 5 $\mathrm{mm}$. In case of the basic model, the maximum generated outlet edge cogging force was $13.4 \mathrm{~N}$ but the Proposed Model \#1 the maximum generated outlet edge cogging force was only $13 \mathrm{~N}$. Although we have adjusted the Xpitch of the auxiliary teeth, we found that the size of the outlet edge's cogging force was not changed greatly. Therefore, we chose the least generated outlet edge cogging force $2.5 \mathrm{~mm}$ as the X-pitch of the auxiliary teeth.

B. The Y-length adjustment of the design parameter of

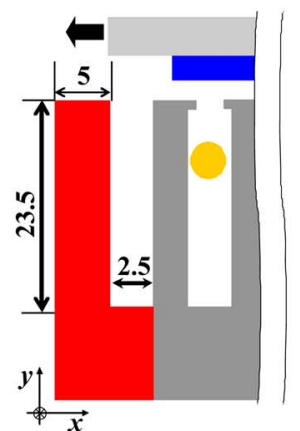

(a)

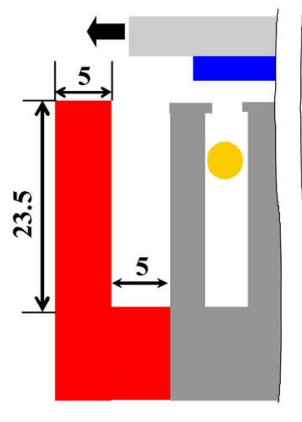

(b)

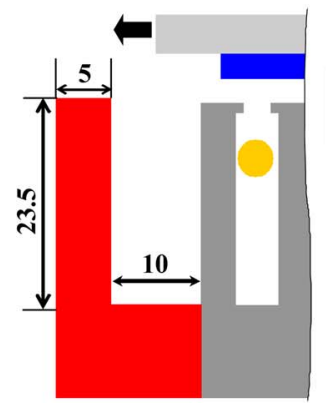

(c)

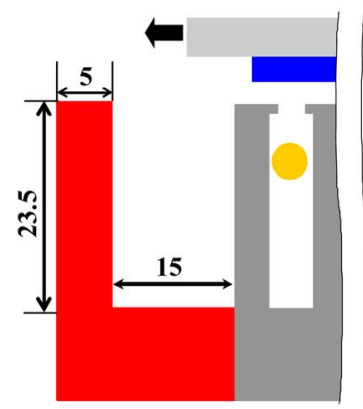

(d)

Fig. 6. (Color online) Shape of auxiliary teeth in case of adjusting X-pitch: (a) proposed model \#1, (b) proposed model \#2, (c) proposed model \#3, (d) proposed model \#4. 


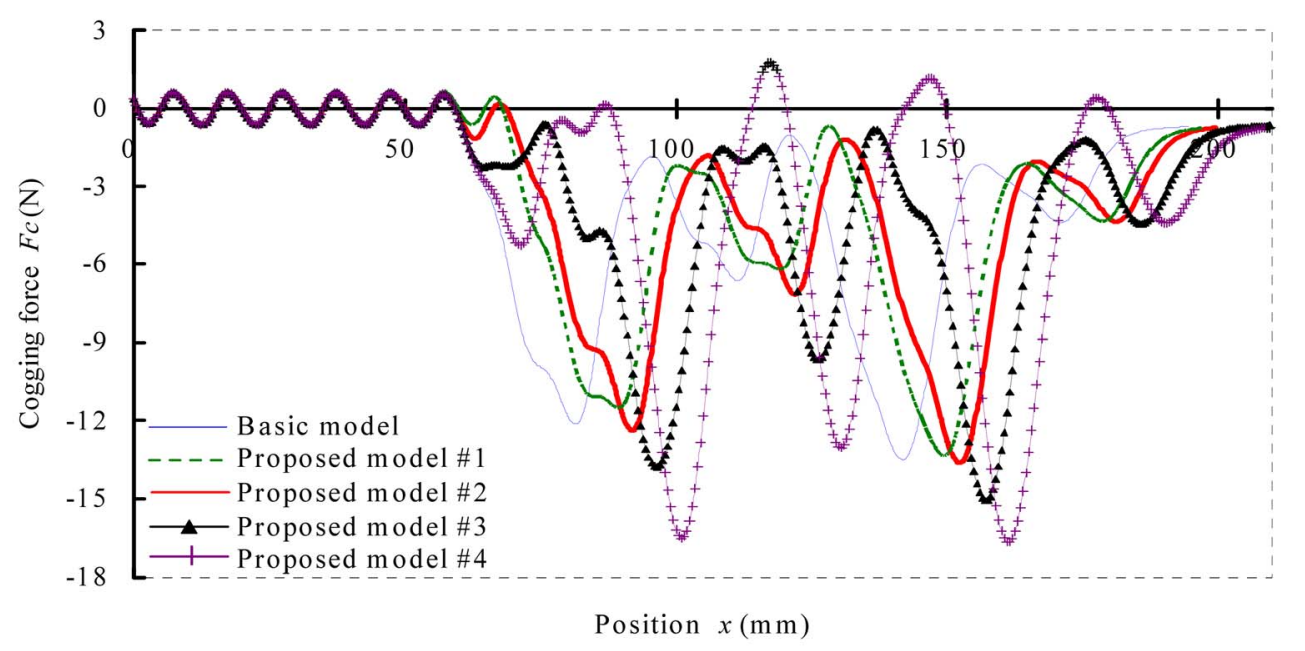

Fig. 7. (Color online) Waveforms of outlet edge cogging force in case of adjusting X-pitch of auxiliary teeth.

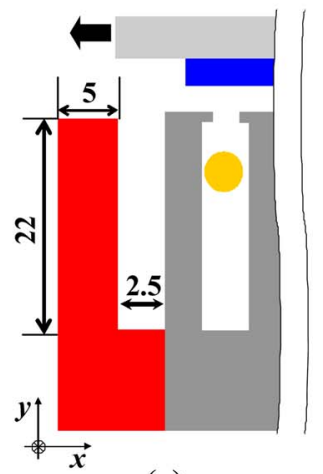

(a)

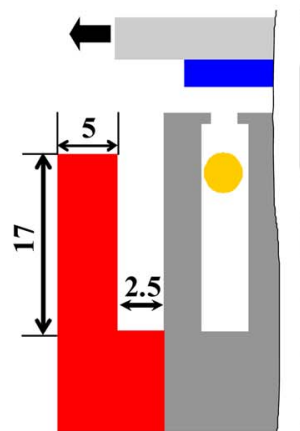

(b)

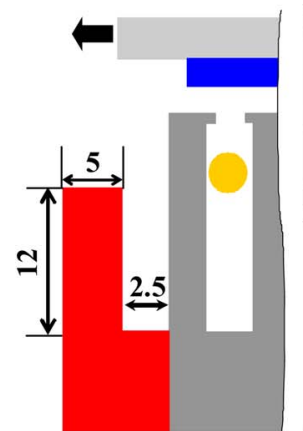

(c)

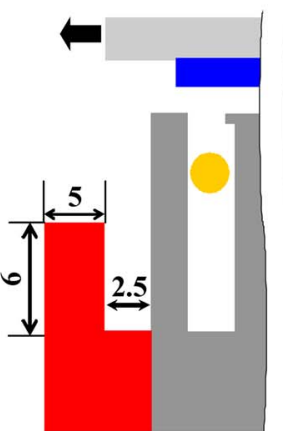

(d)

Fig. 8. (Color online) Shape of auxiliary teeth in case of adjusting Y- length: (a) proposed model \#5, (b) proposed model \#6, (c) proposed model \#7, (d) proposed model \#8.

the auxiliary teeth.

Fig. 8 shows the shape of the auxiliary teeth in case the Y-length of the parameter is adjusted. The Y-length is adjusted $22 \mathrm{~mm}$ for Fig. 8(a), $17 \mathrm{~mm}$ for Fig. 8(b), 12 $\mathrm{mm}$ for Fig. 8(c), and $6 \mathrm{~mm}$ for Fig. 8(d). In this figure, the X-pitch is fixed to $2.5 \mathrm{~mm}$ and the D-length is fixed

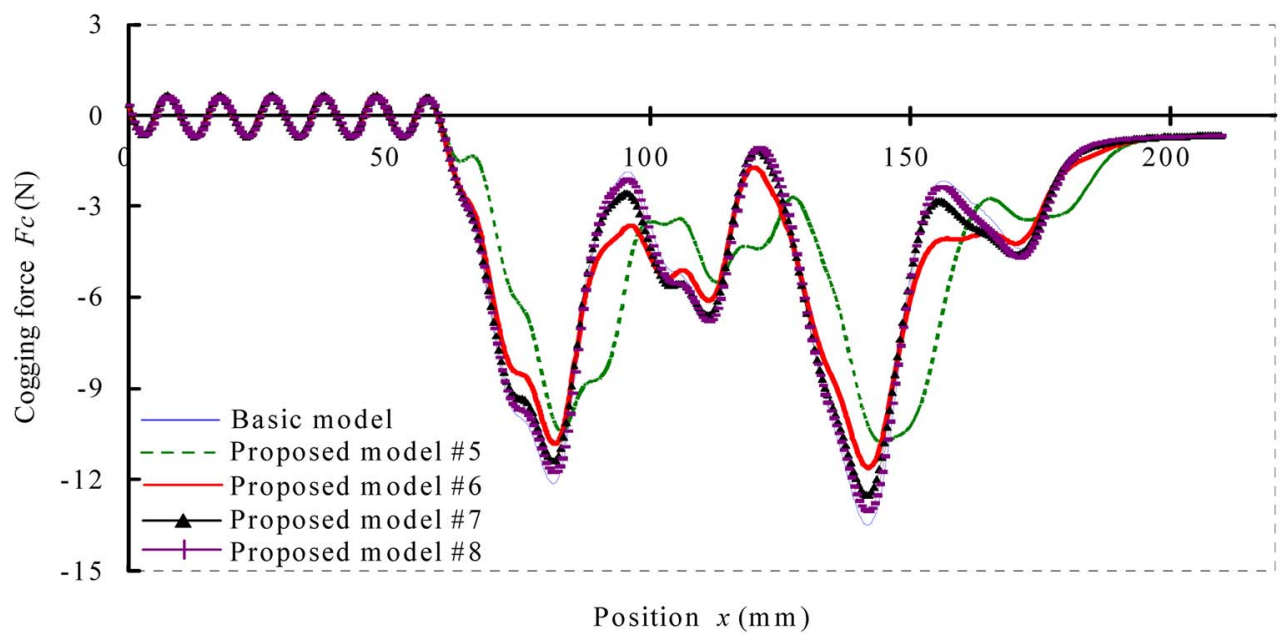

Fig. 9. (Color online) Waveforms of outlet edge cogging force in case of adjusting Y-length of auxiliary teeth. 


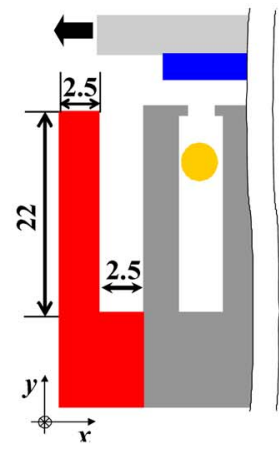

(a)

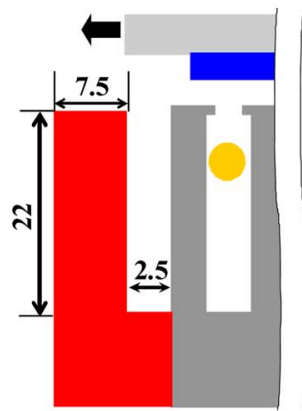

(b)

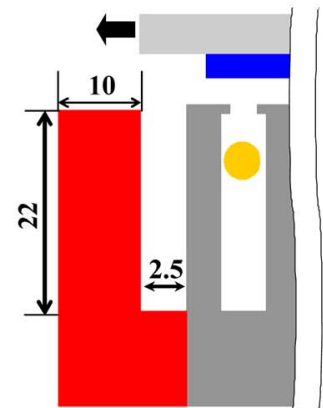

(c)

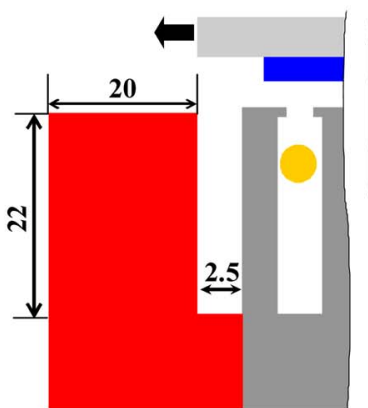

(d)

Fig. 10. (Color online) Shape of auxiliary teeth in case of adjusting D-length: (a) proposed model \#9, (b) proposed model \#10, (c) proposed model \#11, (d) proposed model \#12.

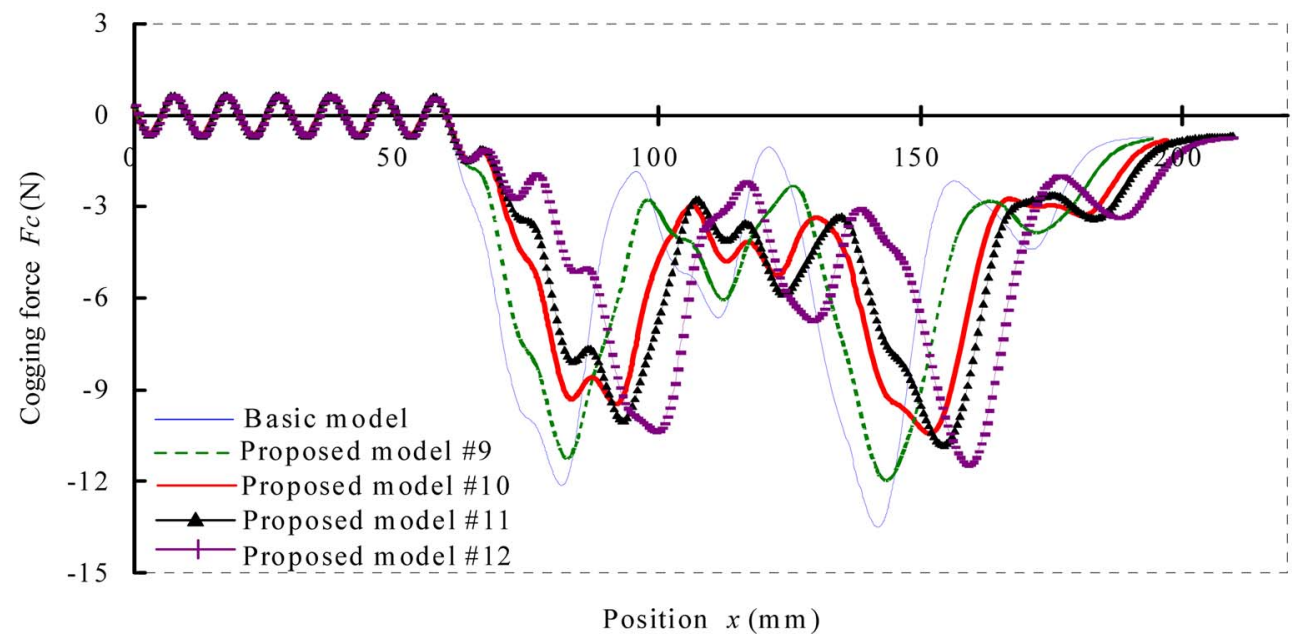

Fig. 11. (Color online) Waveforms of outlet edge cogging force in case of adjusting D-length of auxiliary teeth.

as same as the armature's teeth. Fig. 9 shows the outlet edge cogging force waveforms in case of adjusting Ylength of the auxiliary teeth. As indicated by Fig. 9, we can observe that the outlet edge cogging force is reduced according to the adjustment of Y-length compared to the outlet edge cogging force of the basic model. However, we found that the outlet edge cogging force of the proposed model was reduced compared to the outlet edge cogging force of the basic model when the $23.5 \mathrm{~mm}$ of $\mathrm{Y}$ length was cut more than a quarter, but the difference was extremely small, thus insignificant. Between the proposed model \#5 and proposed model \#6 with reduced Y-length under a quarter, proposed model \#5 showed the most reduced outlet edge cogging force with the maximum cogging force of $10.3 \mathrm{~N}$. Therefore, we chose $22 \mathrm{~mm}$ as the Y-length which has generated the least outlet edge cogging force among the proposed models.

C. The D-length adjustment of the design parameter of the auxiliary teeth

Fig. 10 shows the shape of the auxiliary teeth in case the D-length of the parameter is adjusted. The D-length is adjusted $2.5 \mathrm{~mm}$ for Fig. 10(a), $7.5 \mathrm{~mm}$ for Fig. 10(b), 10 $\mathrm{mm}$ for Fig. 10(c), and $20 \mathrm{~mm}$ for Fig. 10(d). In this figure, the X-pitch is fixed to $2.5 \mathrm{~mm}$ and the Y-length is fixed to $22 \mathrm{~mm}$ which has generated the least outlet edge cogging force. Fig. 11 shows the outlet edge cogging force waveforms in case of adjusting D-length of the auxiliary teeth. As indicated in Fig. 11, we found that the outlet edge cogging force is also reduced according to the adjustment of D-length compared to the outlet edge cogging force of the basic model. Moreover, when the Dlength of the auxiliary teeth was adjusted between 2.5 $\mathrm{mm}-20 \mathrm{~mm}$, the cogging force of the outlet edge was slightly increased with a focus on $7.5 \mathrm{~mm}$ of D-length. In case of the basic model the maximum outlet edge cogging force was $13.4 \mathrm{~N}$ but the maximum outlet edge cogging force of the proposed model \#10 which showed most 
reduced outlet edge cogging force among the proposed models reached $9.6 \mathrm{~N}$. Therefore, we selected $7.5 \mathrm{~mm}$ as the D-length of the auxiliary teeth's width parameter.

\section{Conclusion}

In this paper, we focused on the cogging force of the outlet edge in a stationary discontinuous armature PMLSM, which features a discontinuous arrangement of the LSM's armature. From the results of a 2-D numerical analysis with a FEM, we could confirm that the cogging force of the outlet edge is a maximum of $13.4 \mathrm{~N}$. Moreover, to the reduce outlet edge cogging force, which affects the instrument's output or driving characteristics, we proposed models whose armature outlet edges had the auxiliary teeth, and we examined them by using a 2-D numerical analysis with a FEM. We discovered that a $28.4 \%$ reduction of the outlet edge cogging force was possible when using proposed model \#10, compared with the basic model.

Based on this result, we found that if we install the auxiliary teeth as the outlet edge cogging force reduction method, the appropriate pitch of the auxiliary teeth is 2.5 $\mathrm{mm}$, height of the auxiliary teeth is $22 \mathrm{~mm}$, and width of the auxiliary teeth is $7.5 \mathrm{~mm}$, respectively.

\section{Acknowledgements}

This study was supported by research fund from Chosun University, 2010.

\section{References}

[1] R. Akmese and J. F. Eastham, IEEE Trans. Magn. 28, 3042 (1992).

[2] M. Sanada, S. Morimoto, and Y. Takeda, IEEE Trans. Industry Appl. 33, 966 (1997).

[3] J. Chang, J. Kim, D. Kang, and D. Bang, J. Magnetics 15, 64 (2010).

[4] Y. Kim and S. Jung, J. Magnetics 14, 47 (2009).

[5] Y. Kim, H. Dohmeki, and D. Ebihara, IET Electric Power Appl. 153, 585 (2006). 